\title{
ERROS CONCEITUAIS DE SISTEMÁTICA VEGETAL EM LIVROS DIDÁTICOS DE BIOLOGIA DO PNLD
}

\author{
CONCEPTUAL ERRORS OF PLANT SYSTEMATICS IN PNLD \\ BIOLOGY TEXTBOOKS
}

\author{
ERRORES CONCEPTUALES DE LA BOTÁNICA SISTEMÁTICA EN LIBROS \\ DIDÁCTICOS DE BIOLOGÍA DEL PNLD
}

\author{
Gustavo Bellini Monteiro ${ }^{1}$; Luciana Bastos Ferreira ${ }^{2}$
}

\begin{abstract}
Resumo
Muitos professores utilizam livros didáticos como principal material de apoio para suas aulas. No Brasil, esses livros são distribuídos para as escolas públicas pelo Programa Nacional do Livro Didático (PNLD). O objetivo deste trabalho foi identificar erros conceituais de Sistemática Vegetal nos livros de Biologia do PNLD 2018. O conteúdo de Sistemática Vegetal foi analisado nas 10 obras, buscando-se por erros conceituais, que foram então categorizados. Foram encontrados 58 tipos de erros, sendo 57\% sobre "reprodução", seguidos por "evolução" $(28 \%)$ e "taxonomia" (15\%). Esta pesquisa revelou que os livros didáticos analisados apresentam diversos pontos em dissonância com a epistemologia da escola filogenética, o que pode prejudicar o "pensar em árvore", uma das principais competências para a alfabetização científica.
\end{abstract}

Palavras-chave: Ensino de Botânica; Materiais didáticos; "Pensar em árvore"; Sistemática Filogenética; Conteúdo conceitual.

\begin{abstract}
Many teachers use textbooks as the main support material for their classes. In Brazil, these books are distributed to public schools by the National Textbook Program (PNLD). The objective of this work was identifying conceptual errors in Plant Systematics in PNLD 2018 Biology books. The content of Plant Systematics was analyzed in 10 works, looking for conceptual errors, which were then categorized. 58 types of errors were found, with 57\% about "reproduction", followed by "evolution" (28\%) and "taxonomy" (15\%). This research revealed that the analyzed textbooks present several points in dissonance with the epistemology of the phylogenetic school, which can harm "tree thinking", one of the main competences for scientific literacy.
\end{abstract}

Keywords: Botany teaching; Teaching materials; "Tree Thinking"; Phylogenetic Systematics; Conceptual content.

\footnotetext{
${ }^{1}$ Licenciado em Ciências Biológicas - Instituto Federal de Educação, Ciência e Tecnologia de São Paulo (IFSP). São Paulo, SP - Brasil. Mestrando do Programa de Ensino e História das Ciências e Matemática da Universidade Federal do ABC. Santo André, SP - Brasil. Professor de Educação Básica II - Secretaria da Educação do Estado de São Paulo. São Paulo, SP - Brasil. E-mail: bellini.gu@ hotmail.com

${ }^{2}$ Doutora em Ciências - Botânica - Universidade de São Paulo (USP). São Paulo, SP - Brasil. Professora de ensino básico, técnico e tecnológico - Instituto Federal de Educação, Ciência e Tecnologia de São Paulo (IFSP). São Paulo, SP - Brasil. E-mail: luciana.bastos@ifsp.edu.br
} 


\section{Resumen}

Muchos professores utilizan los libros de texto como principal material de apoyo para sus clases. En Brasil, estos libros son distribuidos a las escuelas públicas por el Programa Nacional do Livro Didático - Programa Nacional de Libros de Texto - $(P N L D)$. El objetivo de este trabajo fue identificar errores conceptuales en Botánica Sistemática en los libros de Biología del PNLD 2018. Se analizó el contenido de Botánica Sistemática en los 10 trabajos, buscando errores conceptuales, que luego fueron categorizados. Se encontraron 58 tipos de errores, el $57 \%$ en "reproducción", seguido de "evolución" (28\%) y "taxonomía" (15\%). Esta investigación reveló que los libros de texto analizados presentan varios puntos en disonancia con la epistemología de la escuela filogenética, lo que puede dañar el "pensamiento en árbol", una de las principales competencias para la alfabetización científica.

Palabras clave: Enseñanza de la botánica; Materiales de enseñanza; "Pensamiento en árbol"; Sistemática filogenética; Contenido conceptual.

$$
* * *
$$

\section{Introdução}

O ensino de Botânica é de fundamental importância para a formação dos estudantes de ensino básico. As plantas fazem parte do cotidiano da humanidade, tanto nos aspectos mais diretos (tais como vestuário, medicina e alimentação), quanto em outros menos óbvios, como regulação térmica e redução de ruídos nas grandes cidades (AMATO-LOURENÇO et al., 2016) e até mesmo contribuição para a sensação de bem-estar e qualidade de vida (DRAVIGNE et al., 2008). Apesar da enorme importância desses organismos para a vida humana, as plantas podem passar despercebidas para boa parte das pessoas caso não haja uma intenção, por parte dos professores, de diminuir a "cegueira botânica" de seus estudantes (NEVES et al., 2019).

Ensinar Botânica tem se mostrado uma tarefa bastante desafiadora, não apenas no Brasil como em outros países do mundo (HERSHEY, 1996; URSI et al., 2018). O que se tem observado é que a Botânica tem sido ensinada de maneira muito teórica e desestimulante, centrada na aprendizagem de nomenclaturas e definições (KINOSHITA et al., 2006), o que resulta em pouco interesse e baixo rendimento dos estudantes na disciplina (NOGUEIRA, 1997). Somando-se a isso, livros didáticos costumam apresentar as plantas de forma extremamente descritiva, com termos de difícil assimilação associados a figuras que nem sempre são condizentes com a realidade, além da falta de um enfoque evolutivo (FRENEDOZO et al., 2005). Esses fatores podem contribuir negativamente para a visão que os estudantes têm das plantas e da Botânica e impedir o desenvolvimento do "pensar em árvore" (tree thinking), que, segundo Novick e Catley (2016), é uma das competências fundamentais para alfabetização científica (e biológica) no século XXI e que envolve, dentre muitas habilidades, a capacidade de ler e construir cladogramas.

A utilização da perspectiva filogenética no ensino de Biologia pode permitir uma abordagem comparativa da vida, diminuindo, assim, a distância entre os grupos de seres vivos (GUIMARÃES, 2005), o que vai de encontro à maneira fragmentada pela qual a Biologia normalmente é ensinada e apresentada nos livros didáticos, com a diversidade da vida aparecendo nas descrições morfofisiológicas dos vários grupos, sem que se estabeleçam relações entre eles (KRASILCHICK, 2004). 
DOI: http://doi.org/10.46667/renbio.v14i1.414

Os livros didáticos têm uma grande importância no ensino, uma vez que são as fontes de informação mais utilizadas em sala de aula e, em muitos casos, os únicos materiais de apoio didático disponíveis para estudantes e professores (VASCONCELOS; SOUTO, 2003). No Brasil, esses livros são avaliados e distribuídos de forma regular, sistemática e gratuita pelo Programa Nacional do Livro e do Material Didático (PNLD) desde 1985. As obras são inscritas pelos detentores de direitos autorais (editoras), conforme critérios estabelecidos em edital, e avaliadas pedagogicamente por especialistas de diferentes áreas, vinculados ao Ministério da Educação (MEC), os quais levam em conta critérios como: conceitos e conhecimentos, ilustrações, linguagem, proposta pedagógica, orientação à pesquisa, adequação ao público-alvo, ética e cidadania (BRASIL, 2011; FRANÇA; MARGONARI; SCHALL, 2011).

Uma vez aprovadas pelo MEC, as obras comporão o Guia Digital do PNLD, que orienta o corpo docente e o corpo diretivo das escolas na escolha das coleções. A distribuição dos livros é feita por meio de um contrato entre o Fundo Nacional de Desenvolvimento da Educação (FNDE) e os Correios, que as leva diretamente da editora para as escolas que se inscreveram no PNLD e participaram do último Censo Escolar (BRASIL, 2011). Mesmo com essa avaliação, as obras disponibilizadas pelo PNLD apresentam problemas que podem comprometer o aprendizado dos alunos (CARDOSO-SILVA; OLIVEIRA, 2013).

Em relação aos problemas encontrados nos livros didáticos, cabe um apontamento sobre as dificuldades inerentes à transposição didática realizada pelos autores desses materiais. Transposição didática, de acordo com Chevallard (1991), é um processo que se dá em duas etapas. A primeira delas envolve a transformação do saber sábio em saber a ser ensinado, que é um novo saber que se encontra mais próximo da escola. O saber a ser ensinado, que comumente se encontra nos livros didáticos e nos currículos, sofre então uma segunda transposição e se torna o saber ensinado, que corresponde ao saber modificado pelo professor, visando a uma melhor compreensão pelos alunos durante as aulas (SIQUEIRA; PIETROCOLA, 2006).

Os erros conceituais presentes em livros didáticos, portanto, correspondem a falhas na primeira etapa da transposição didática e podem distanciar ainda mais o saber sábio (científico) do saber a ser ensinado. Uma vez que a referência para o saber a ser ensinado é, necessariamente, o saber sábio, um distanciamento muito grande dele pode fazer com que os conteúdos ensinados na escola percam sentido; afinal, a Biologia é uma área da Ciência e, como tal, seus saberes são produzidos na Academia, e não na escola (LOPES, 2015).

Dessa forma, é de grande valor a realização de pesquisas que visem avaliar a qualidade dos conteúdos abordados em livros didáticos (XAVIER; FREIRE; MORAES, 2006). As pesquisas que identificam erros conceituais nesses materiais podem ser indicadores úteis de conceitos potencialmente confusos para os estudantes e professores e, assim, mereceriam maior atenção e até uma revisão por parte dos autores e editores (HERSHEY, 2005). 
DOI: http://doi.org/10.46667/renbio.v14i1.414

Embora existam, na literatura, trabalhos publicados que tenham se proposto a analisar o conteúdo de Botânica em livros didáticos (SILVA et al., 2009; SARTIN et al., 2012; PATATT; ARAÚJO, 2013; CHECOM, AOYAMA, 2014; MARINHO; SETÚVAL; AZEVEDO, 2015; RIBEIRO; GÜLLICH, 2017; SOUZA; GARCIA, 2019), nenhum deles se aprofundou em questões específicas do conteúdo de Sistemática Vegetal. Essa área da Botânica estuda a diversidade, a evolução e a classificação das plantas (Embryophyta ou Plantae sensu strictissimo) e boa parte dos caracteres utilizados para classificá-las está relacionada a aspectos reprodutivos.

Se o ensino de Sistemática Vegetal na educação básica tiver como princípio o agrupamento de seres vivos por meio de suas homologias compartilhadas (SANTOS; CALOR, 2008), além de fazer com que a biodiversidade tenha mais sentido para os estudantes, ele pode contribuir para o desenvolvimento da competência de "pensar em árvore".

Considerando-se a grande quantidade de pesquisas que apontam problemas em livros didáticos, uma pergunta foi levantada pelos autores do presente trabalho: haveria problemas também na temática Sistemática Vegetal em materiais didáticos voltados para o ensino médio, a última etapa do ensino básico em nosso país? O presente trabalho, portanto, teve como objetivo identificar os erros conceituais de Sistemática Vegetal em livros didáticos de Biologia do PNLD, que têm grande inserção nas escolas públicas brasileiras e, portanto, atingem uma grande quantidade de professores e estudantes.

\section{Procedimentos metodológicos}

\subsection{Identificação das obras}

Foram analisadas as 10 obras de Biologia do PNLD 2018, disponíveis no Guia Digital (BRASIL, 2017). As coleções, divididas em três volumes, correspondem às séries do ensino médio. Foram selecionados para análise exclusivamente os volumes que continham capítulo (s) específico (s) sobre o conteúdo de Sistemática Vegetal. Para facilitar as análises, as coleções foram enumeradas (Quadro 1). 
DOI: http://doi.org/10.46667/renbio.v14i1.414

Quadro 1: Livros de Biologia do PNLD 2018 utilizados para análise neste trabalho.

\begin{tabular}{|c|c|c|c|c|c|}
\hline Número & Autor(es) & Nome do livro & Editora & Ano & Volume \\
\hline 1 & $\begin{array}{l}\text { AMABIS, J. M.; MARTHO, G. } \\
\text { R. }\end{array}$ & Biologia Moderna & Moderna & 2016 & 2 \\
\hline 2 & BIZZO, N. M. V. & $\begin{array}{l}\text { Integralis - Biologia: } \\
\text { novas bases }\end{array}$ & IBEP & 2016 & 2 \\
\hline 3 & CATANI, A. et al. & $\begin{array}{l}\text { Ser protagonista - } \\
\text { Biologia }\end{array}$ & Edições SM & 2016 & 2 \\
\hline 4 & FAVARETTO, J. A. & $\begin{array}{c}\text { Biologia: } \\
\text { Unidade e Diversidade }\end{array}$ & FTD & 2016 & 2 \\
\hline 5 & $\begin{array}{l}\text { LINHARES, S.; PACCA, H. } \\
\text { GEWANDSZNAJDER, F.; }\end{array}$ & Biologia Hoje & Ática & 2017 & 2 \\
\hline 6 & LOPES, S. G. B. C.; ROSSO, S. & Bio & Saraiva & 2016 & 2 \\
\hline 7 & MENDONÇA, V. L. & Biologia & AJS & 2016 & 2 \\
\hline 8 & OGO, M. Y.; GODOY, L. P. & \#Contato Biologia & Quinteto & 2016 & 2 \\
\hline 9 & RIOS, E. P.; THOMPSON, M. & $\begin{array}{l}\text { Conexões com a } \\
\text { Biologia }\end{array}$ & Moderna & 2016 & 3 \\
\hline 10 & $\begin{array}{l}\text { SILVA JR., C.; SASSON, S.; } \\
\text { CALDINI JR, N. }\end{array}$ & Biologia & Saraiva & 2016 & 2 \\
\hline
\end{tabular}

Fonte: Elaborado pelos autores.

\subsection{Critérios de análise}

Os procedimentos de análise constituíram, primeiramente, a seleção dos capítulos referentes ao conteúdo de Sistemática Vegetal em cada obra, levando-se em conta apenas a abordagem teórica do conteúdo, com foco nos erros conceituais. Para identificar esses erros, foram feitas leituras minuciosas dos textos explicativos, buscando argumentos que apresentassem inconsistências teóricas. Para confirmar essas inconsistências, foram utilizados como referência o livro de Simpson (2010), uma obra clássica de Sistemática Vegetal para o ensino superior, além de artigos recentes de propostas de filogenias para grupos de embriófitas: APG IV (2016) e PPG I (2016).

Os erros conceituais encontrados foram classificados de duas maneiras: I, temática dentro do conteúdo de Sistemática Vegetal, tendo sido criadas pelos autores três categorias: "evolução", "taxonomia" e "reprodução" e II, tipo de erro, seguindo quatro das cinco categorias estabelecidas por Hershey (2004) dos tipos mais comuns de erros em Botânica. São elas, em tradução livre a partir do original em inglês: "sobregeneralizações" (overgeneralizations); "sobressimplificações" (oversimplifications); "conceitos e termos obsoletos" (obsolete concepts and terms) e "identificações errôneas" (misidentifications). Embora Hershey (2004) não tenha explicitado em seu artigo os significados de cada uma dessas categorias, podemos definir uma "sobregeneralização" como a atribuição de um caráter geral a um conhecimento particular (FRANZOLIN et al., 2014). No presente trabalho, considerou-se que "sobressimplificação" é uma transformação de conceitos complexos em simples, trazendo explicações falhas ao se omitir outros conceitos, etapas ou processos relacionados com aquilo 
DOI: http://doi.org/10.46667/renbio.v14i1.414

que se pretende ensinar. "Conceito ou termo obsoleto" se refere ao uso de nomenclaturas ou definições desatualizadas ou em desuso pela comunidade científica. Por fim, considerou-se como "identificação errônea" a identificação ou nomeação incorreta de estruturas ou processos, que deveriam ter sido identificados ou nomeados com outros termos.

Os erros específicos da categoria "evolução das plantas" foram classificados também seguindo, com adaptações, três das seis categorias propostas por Lopes e Vasconcelos (2012), os quais identificaram equívocos relativamente frequentes no ensino de Filogenia. São elas: "evolução como um processo com finalidade específica", "evolução como uma sequência linear com grupos atuais se transformando em outros grupos atuais" e "evolução direcional".

\section{Resultados e Discussão}

Todos os livros didáticos analisados nesta pesquisa apresentaram algum tipo de distorção conceitual ao abordar o conteúdo de Sistemática Vegetal. Ao todo, foram encontrados 154 erros conceituais. Como muitos desses erros se repetiram em várias obras, os erros idênticos foram agrupados, resultando ao final em 58 erros conceituais. Desses, 33 (57\%) se referem à temática "reprodução", seguidos das temáticas "evolução" (28\%) e "taxonomia" (15\%). A seguir, encontram-se os resultados organizados a partir dessas temáticas, para melhor apresentação e discussão.

\subsection{Erros referentes à temática "reprodução das plantas"}

A temática "reprodução" foi a que apresentou maior quantidade de erros conceituais, uma vez que é um assunto com muitos detalhes e com grande enfoque dado pelos livros, principalmente aos ciclos de vida dos grupos de plantas. De acordo com Macedo et al. (2012) esse é um dos assuntos que os professores de Biologia relatam ser o mais complexo para se ensinar. Spiro e Knisely (2008) consideram esse conteúdo um dos pontos mais desafiadores da área da Botânica, principalmente no que tange à sua transposição didática.

Dentro da temática, a maioria dos erros (48\%) se enquadra em "sobregeneralizações". Os erros menos frequentes se enquadram respectivamente em "identificações errôneas" (42\%) e "sobressimplificações" (10\%). Não foi encontrado nenhum erro do tipo "conceito ou termo obsoleto". Alguns trechos de argumentos dos erros mais comuns dessa temática se encontram listados no Quadro 2. 
DOI: http://doi.org/10.46667/renbio.v14i1.414

Quadro 2: Tipo de erros conceituais e trechos de alguns argumentos sobre "reprodução das plantas" presentes nos livros didáticos nos quais se detecta (em negrito) esses erros.

\begin{tabular}{|c|c|}
\hline $\begin{array}{l}\text { Tipo de Erro } \\
\text { Conceitual }\end{array}$ & Argumento \\
\hline \multirow[t]{3}{*}{ Sobregeneralização } & "Fala-se então em dupla fecundação, uma característica exclusiva das angiospermas". \\
\hline & $\begin{array}{l}\text { "(...) o gametófito feminino [das angiospermas], o qual é ainda mais simples que o das } \\
\text { gimnospermas. Ele é formado por apenas oito células, sendo uma delas a oosfera e outras duas } \\
\text { chamadas núcleos polares”. }\end{array}$ \\
\hline & $\begin{array}{l}\text { "A grande diferença reside no fato de os dois sexos estarem no mesmo gametófito [das } \\
\text { pteridófitas], que é dito hermafrodita". }\end{array}$ \\
\hline $\begin{array}{l}\text { Identificação } \\
\text { errônea }\end{array}$ & $\begin{array}{l}\text { "Os esporos masculino e feminino [das gimnospermas] se desenvolvem em gametófitos masculino } \\
\text { e feminino respectivamente". }\end{array}$ \\
\hline Sobressimplificação & “(...) os grãos de pólen são produzidos em grande quantidade, por meiose”. \\
\hline
\end{tabular}

Fonte: Elaborado pelos autores.

Como há uma variação enorme dentro e entre os grupos de plantas com relação a detalhes referentes à reprodução, essa diversidade acabou sendo subestimada em diversas obras, como nos exemplos a seguir.

Os livros 2, 6, 7 e 8 consideram que a dupla fecundação é um fenômeno exclusivo das angiospermas. Embora a dupla fecundação de fato seja considerada uma novidade evolutiva das angiospermas de acordo com o APG IV (2016), ela não é exclusiva do grupo. Em Ephedra e Gnetum (gimnospermas gnetófitas) ocorre também o evento da dupla fecundação, o que caracteriza convergência evolutiva (RAN et al., 2018). Tal erro poderia ter sido evitado se os autores não utilizassem o termo "exclusivo" para se referir a essa novidade evolutiva.

Cerca de $60 \%$ dos livros descrevem a estrutura do saco embrionário das angiospermas como sendo composta por sete células e oito núcleos. Porém, esse padrão de megasporogênese e megagametogênese, do tipo Polygonum, ocorre em cerca de $70 \%$ das angiospermas atuais. $\mathrm{O}$ padrão dos outros $30 \%$ pode variar (SIMPSON, 2010). Tal erro poderia ter sido evitado se os autores tivessem acrescentado a expressão "na maior parte das angiospermas" ou se não especificassem a quantidade de células, como fez o livro 6.

Nos livros 2, 6, 7 e 9 afirma-se que o protalo é uma estrutura hermafrodita. No entanto, algumas espécies de samambaias leptosporangiadas aquáticas da família Marsilaceae, são heterosporadas, produzindo protalos masculinos e femininos (SIMPSON, 2010).

Um tipo de erro de "identificação errônea" comumente encontrado foi a denominação de micrósporos e megásporos como esporos masculinos e femininos, respectivamente, como aparece nas obras 2, 3 e 9. Os esporos são células haploides que dão origem a gametófitos, sem que ocorra a fusão com outra célula (SIMPSON, 2010) e, dessa maneira, os termos "masculino" e "feminino" não se aplicam a eles. Esse tipo de erro pode induzir os estudantes a considerar 
DOI: http://doi.org/10.46667/renbio.v14i1.414

que os esporófitos apresentam sexo, o que não é correto, uma vez que os esporófitos apenas portam esporângios, que podem dar origem a micrósporos, megásporos ou aos dois.

O exemplo de erro do tipo "sobressimplificação" foi a afirmação de que os grãos de pólen são produzidos por meiose, quando o correto seria afirmar que a meiose origina os micrósporos e estes é que posteriormente originam grãos de pólen (SIMPSON, 2010). Embora esse erro só tenha aparecido no livro 10, ele é relevante, pois omite informações de uma das etapas mais importantes do ciclo de vida das espermatófitas, que é o momento de ocorrência da meiose e das estruturas celulares que esse tipo de divisão origina.

\subsection{Erros referentes à temática "evolução das plantas"}

Ao todo, foram encontrados 15 tipos de erros dessa temática, sendo que todos podem ser considerados "identificações errôneas" acerca da evolução das plantas e de conceitos e termos vinculados ao processo evolutivo. Embora esses erros não se refiram diretamente às leituras de cladogramas, e sim a textos presentes nos livros, percebe-se que são decorrentes de pesquisas falhas e interpretações possivelmente equivocadas de filogenias por parte dos autores. O quadro 3 apresenta alguns trechos de argumentos dos erros mais comuns dessa temática.

É importante destacar que, embora todas as obras analisadas utilizem cladogramas como forma de ilustrar as relações de parentesco entre as plantas, foram notadas incoerências entre o que as imagens mostram e o que está expresso nos textos. As diversas distorções conceituais referentes à sistemática filogenética encontradas nos livros didáticos ilustram que a mera presença de cladogramas nos capítulos referentes à sistemática vegetal não é suficiente para o desenvolvimento da competência de "pensar em árvore", conforme explicado nos parágrafos a seguir.

Quadro 3: Tipo de erros conceituais e trechos de alguns argumentos sobre "evolução das plantas" presentes nos livros didáticos nos quais se detecta (em negrito) esses erros.

\begin{tabular}{|l|l|}
\hline \multicolumn{1}{|c|}{ Tipo de Erro Conceitual } & \multicolumn{1}{|c|}{ Argumento } \\
\hline $\begin{array}{l}\text { Evolução como um processo com finalidade } \\
\text { específica }\end{array}$ & $\begin{array}{l}\text { "O surgimento do grão de pólen e do tubo polínico foi condição } \\
\text { importante para a conquista definitiva do ambiente terrestre pelas } \\
\text { plantas". }\end{array}$ \\
\hline $\begin{array}{l}\text { Evolução como uma sequência linear com } \\
\text { grupos atuais se transformando em outros } \\
\text { grupos atuais }\end{array}$ & $\begin{array}{l}\text { "As plantas terrestres evoluíram de um grupo de algas verdes, as } \\
\text { carófitas, também conhecidas como carofíceas". }\end{array}$ \\
\cline { 2 - 2 } & $\begin{array}{l}\text { "O surgimento das gimnospermas trouxe novidades evolutivas, como } \\
\text { a presença da semente e do grão de pólen". }\end{array}$ \\
\hline Evolução direcional & $\begin{array}{l}\text { "Na evolução das plantas terrestres, verifica-se que houve redução da } \\
\text { fase gametofítica e maior desenvolvimento da esporofítica". }\end{array}$ \\
\hline
\end{tabular}

Fonte: Elaborado pelos autores. 
DOI: http://doi.org/10.46667/renbio.v14i1.414

Um erro muito comum, presente nas obras 2, 5, 7, 8, 9 e 10, são as assertivas de que as plantas "conquistaram" o meio terrestre ou que desenvolveram estratégias para isso, o que pode levar os leitores a pensarem que o processo evolutivo está relacionado a um propósito prédeterminado em uma perspectiva teleológica, a qual não é aceita nos modelos científicos (SEPULVEDA; EL-HANI, 2007), já que a seleção natural não pode equipar uma espécie para encarar novas contingências e não tem qualquer propósito ou direção (FUTUYMA, 1996).

Esse erro conceitual traz consigo outro problema: uma visão equivocada e muito presente no ensino de evolução de considerar o processo evolutivo como uma scala naturae. El-Hani e Kawasaki (2002) relatam que essa abordagem está presente na forma como os seres vivos são ordenados nos livros didáticos, a partir dos menos complexos aos mais complexos, o que favorece uma visão de progresso e aperfeiçoamento da evolução.

A visão de scala naturae aparece nos livros em argumentos de que as plantas se tornaram cada vez mais bem adaptadas aos ambientes de baixa umidade e que com o surgimento das angiospermas a evolução das plantas teria se encerrado, já que que o grupo seria o ápice da evolução. A perpetuação de equívocos como estes pode ser levada até o ensino superior. Bizotto et al. (2016), em seu estudo com 164 estudantes do primeiro ano do Bacharelado em Ciência e Tecnologia da Universidade Federal do ABC, constataram que muitos deles relacionam evolução à ideia de progresso e aumento de complexidade, e que as angiospermas são o grupo "mais evoluído" dentre os vegetais.

Outro tipo de erro encontrado nas obras avaliadas no presente trabalho é considerar a evolução como um processo linear, com grupos atuais se transformando em outros grupos atuais, desconsiderando que a evolução ocorre em forma de "árvore". O livro 10, por exemplo, afirma que as plantas terrestres se originaram das algas verdes carofíceas, que são um grupo atual de algas, quando o correto seria afirmar que certas algas verdes carofíceas são um grupo-irmão de Embryophyta, não o grupo ancestral delas (SIMPSON, 2010). Confundir grupo-irmão com ancestral é um dos erros mais comuns em Sistemática Filogenética (GREGORY, 2008) e, no caso desse exemplo, pode levar à interpretação equivocada de que as algas carofíceas se transformaram em plantas, o que estaria de acordo com uma visão transformacionista de evolução que impossibilita o "pensar em árvore".

Essa mesma visão linear da evolução é reforçada nos livros 6, 9 e 10, os quais apresentam trechos que consideram as briófitas ou algas verdes como grupos de transição ou passagem do meio aquático para o terrestre, desconsiderando que esses são grupos atuais e, portanto, não podem representar qualquer transição. Já os livros 2, 3, 4, 5, 6 e 8 afirmam que as sementes e grãos de pólens são novidades evolutivas das gimnospermas. Porém, essas características são novidades evolutivas do clado Spermatophyta (SIMPSON, 2010), surgindo no ancestral do grupo, que inclui as gimnospermas e angiospermas. Uma forma de demonstrar que não há razão, dentro de uma perspectiva filogenética, para afirmar que as sementes surgiram primeiro em gimnospermas seria girar o nó do cladograma correspondente às Spermatophyta e posicionar as angiospermas à esquerda e as gimnospermas à direita. Girar 
DOI: http://doi.org/10.46667/renbio.v14i1.414

os nós de um cladograma é uma estratégia proposta por Gregory (2008) para evitar esse e outros tipos de erros em leitura de cladogramas.

Outro problema encontrado nos livros é a afirmação de que, ao longo da evolução das plantas, houve uma tendência de aumento da fase esporofítica e diminuição da fase gametofítica. Sobre isso é importante pontuar que muitos dos erros conceituais encontrados nos livros didáticos na temática "evolução das plantas" podem ser resultantes de consultas a bibliografias especializadas de Botânica para o ensino superior que se fundamentam em paradigmas evolutivos não filogenéticos. Por exemplo, no livro "Biologia Vegetal de Raven" referência comumente usada no ensino superior no Brasil, ocorre a seguinte citação sobre os gametófitos:

\footnotetext{
"Nas plantas vasculares, entretanto, a evolução do gametófito se caracterizou por uma tendência geral no sentido de redução no seu tamanho e na sua complexidade, sendo os gametófitos de plantas com flores, as angiospermas, os mais reduzidos de todos.” (EVERT, EICHHORN, 2014, p. 398).
}

Tendências evolutivas podem ser definidas como "mudanças direcionais monotônicas consistentes dentro de uma linhagem filética em uma ou mais características" (FUTUYMA, 1996). No entanto, em tradução livre dos autores a partir do original de Gregory (2008): "somente dados históricos ou inferências estatisticamente rigorosas sobre a história, e não uma simples comparação de espécies vivas, podem fornecer suporte convincente para reivindicações de uma tendência evolutiva".

Há consenso na literatura a respeito da redução do gametófito feminino ser uma sinapomorfia de Angiospermae (SIMPSON, 2010). No entanto, isso não é o mesmo que afirmar que houve uma tendência evolutiva para tal redução em Tracheophyta. Monilophyta, por exemplo, é um grupo que apresenta gametófitos relativamente conspícuos (quando comparados aos gametófitos de Angiospermae). Afirmar que houve uma tendência à redução do gametófito feminino em Tracheophyta, portanto, é desconsiderar o caminho evolutivo traçado por outras linhagens de Tracheophyta que não Angiospermae. Além disso, não é possível afirmar que os gametófitos das Monilophyta sejam uma condição ancestral para os gametófitos das Gimnospermae, por exemplo, uma vez que todos esses grupos existem atualmente e, portanto, um não pode ser ancestral do outro. Essa pode ser uma interpretação possível para alguém que que faz uma "leitura através das pontas" de cladogramas (GREGORY, 2008). Uma simples rotação dos nós em um cladograma de Embryophyta permite manter a coerência epistemológica com a teoria filogenética (Figura 1). 
DOI: http://doi.org/10.46667/renbio.v14i1.414

Figura 1: Duas formas de representação da filogenia de plantas terrestres. Em (a) mostrou-se a forma de representação clássica, que transmite a ideia de redução do gametófito (representado por bolinhas verdes) ao longo da evolução. Já em (b), com a rotação de alguns clados, percebe-se que a leitura de uma tendência evolutiva para redução do gametófito é desfeita.

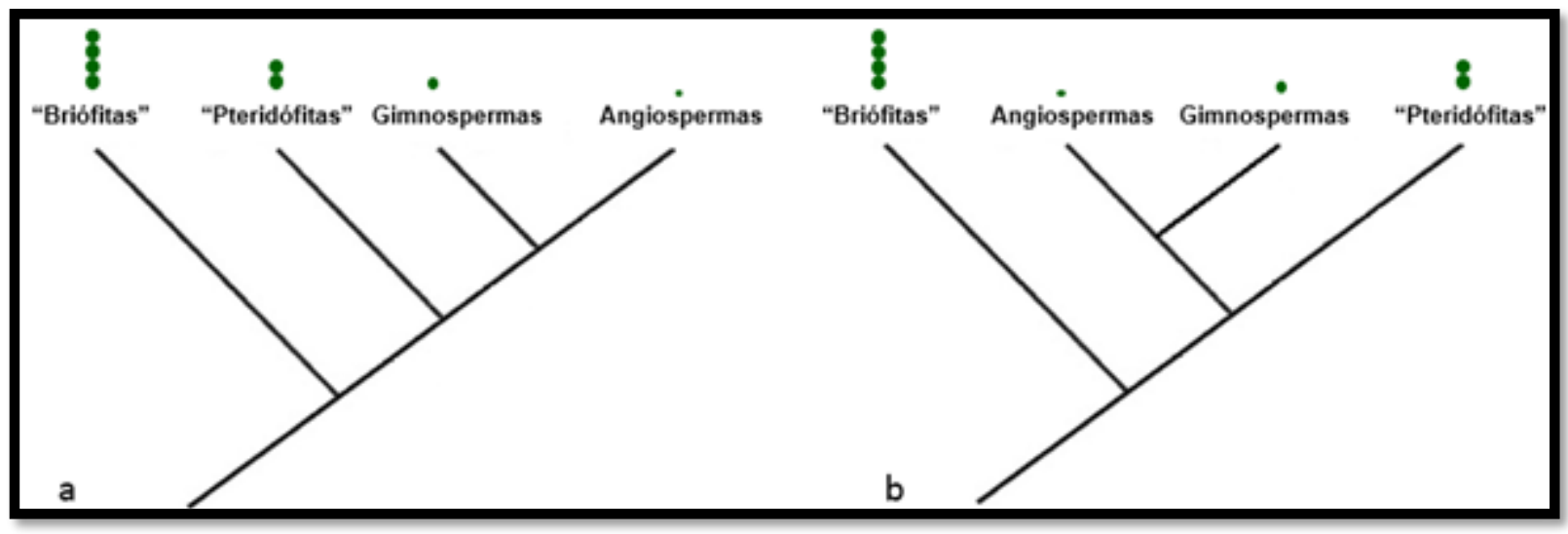

Fonte: Elaborado pelos autores

\subsection{Erros referentes à temática "taxonomia das plantas"}

Os erros conceituais sobre "taxonomia das plantas" foram minoria dentre os encontrados, sendo identificados apenas nove, divididos em dois tipos: "identificações errôneas" (55\%) e "conceitos ou termos obsoletos" (45\%), como aponta o Quadro 4.

A Taxonomia das plantas é apontada como o terceiro conteúdo no qual os alunos têm mais dificuldades em Botânica no ensino médio, de acordo com o estudo de Macedo et al. (2012). Essa dificuldade pode estar vinculada à forma como as plantas têm sido apresentadas nos livros didáticos, o que também foi observado neste trabalho. Sartin et al. (2012) destacam que, nas obras didáticas, a Taxonomia e a classificação de alguns grupos de plantas ainda estão pautadas em uma postura conservadora se comparada às mudanças mais recentes em Sistemática Filogenética. Isso explica as classificações desatualizadas encontradas e que muitas vezes não refletem a história natural dos grupos.

Uma abordagem pautada na história natural e portanto, na presença de homologias para justificar a classificação seria uma maneira de tornar o conteúdo de taxonomia vegetal mais significativo para os estudantes, uma vez que, dessa maneira, ficariam mais explícitos os porquês de um grupo ser considerado mais próximo de um segundo e mais distante de um terceiro, aumentando as possibilidades de reflexão e diminuindo a simples memorização de características de grupos (SANTOS; CALOR, 2008; CORDEIRO et al., 2018). 
DOI: http://doi.org/10.46667/renbio.v14i1.414

Quadro 4: Tipo de erros conceituais e trechos de alguns argumentos sobre "taxonomia das plantas" presentes nos livros didáticos nos quais se detecta (em negrito) esses erros.

\begin{tabular}{|c|l|}
\hline Tipo de Erro Conceitual & \multicolumn{1}{c|}{ Argumento } \\
\hline \multirow{2}{*}{ Identificação errônea } & $\begin{array}{l}\text { “...) as angiospermas são divididas em três grupos: monocotiledôneas (...), eudicotiledôneas } \\
(\ldots) \text { e dicotiledôneas basais”. }\end{array}$ \\
\hline $\begin{array}{c}\text { Conceito ou termo } \\
\text { obsoleto }\end{array}$ & $\begin{array}{l}\text { "As famílias de angiospermas são classicamente divididas em dois grandes grupos, as } \\
\text { monocotiledôneas e as dicotiledôneas". } \\
\text { "Podemos considerar três grupos de pteridófitas, apresentados a seguir: Filicíneas, } \\
\text { Licopodíneas e Equisetíneas". }\end{array}$ \\
\hline
\end{tabular}

Fonte: Elaborado pelos autores.

É importante considerar que, em se tratando de taxonomia, os nomes científicos dos grupos de plantas que aparecem nos livros por si só não se configuram como conteúdo conceitual, mas sim como conteúdo factual, de acordo com a classificação de Zabala (1998). De acordo com esse autor, os conteúdos factuais são fatos, acontecimentos, situações, dados e fenômenos concretos e singulares/pontuais, como a idade de uma pessoa, a data da conquista de um território, a localização ou altura de uma montanha, os nomes, os códigos, os axiomas etc. Como tendem a envolver geralmente a memorização, os erros nesse tipo de conteúdo têm impacto negativo baixo na aprendizagem dos estudantes. Porém, é importante considerar que os conteúdos factuais estão sempre relacionados a um conteúdo conceitual, sendo necessário que os estudantes os aprendam de forma associada e correta.

De acordo com Fidanza (2016), a identificação errônea ou equivocada dos táxons pelos taxonomistas compromete a interpretação de todos os dados acerca da biodiversidade. Do mesmo modo, as identificações errôneas sobre taxonomia que aparecem nos livros levam a uma visão equivocada e errônea da biodiversidade por parte dos alunos.

A identificação errônea mais comum apareceu nos livros 1, 5 e 7, os quais afirmam que os grupos de angiospermas que não se enquadram como eudicotiledônea ou monocotiledônea são consideradas como dicotiledôneas basais (ou angiospermas basais). Quando o termo "angiospermas basais" é utilizado em livros texto voltados ao ensino superior, ele se refere a apenas três grupos: Amborellales, Nymphaeales e Austrobaileyales (JUDD et al., 2009). De acordo com o APG IV (2016), no entanto, as angiospermas são divididas nas seguintes grandes linhagens: Amborellales, Nymphaeales, Austrobaileyales, Magnoliídeas, Chloranthales, Monocotiledôneas, Ceratophyllales e Eudicotiledôneas. As obras 1, 5 e 7, portanto, excluem grupos importantes de angiospermas. Cabe ressaltar, porém, que mesmo em trabalhos de grande importância para a sistemática vegetal, como o APG IV (2016), aparecem trechos que são epistemologicamente incoerentes com a sistemática filogenética. Por exemplo, no referido artigo é utilizado o termo "grado" para o grupo formado por Amborellales, Nymphaeales e Austrobaileyales ("Grado ANA"), um grupo claramente não-monofilético e que deveria ser desconsiderado em um trabalho com abordagem filogenética. 
DOI: http://doi.org/10.46667/renbio.v14i1.414

"Conceitos ou termos obsoletos" são erros que se referem a nomes de táxons já não mais válidos ou a classificações desatualizadas. Dois exemplos relevantes podem ser citados. Nas obras 2, 7 e 10 as angiospermas ainda são divididas em duas classes: monocotiledôneas e dicotiledôneas. O livro 7 chega a citar que essa nomenclatura é clássica e está em desuso, porém não apresenta as novas classificações.

Em relação aos grupos de "pteridófitas", classificações desatualizadas foram encontradas em 70\% dos livros. De acordo com classificações atuais, as "pteridófitas" são agrupadas em duas divisões: Lycopodiophyta (ou Lycophyta) e Monilophyta (PPG I, 2016) que formam um grupo parafilético. Portanto, "Pteridophyta" não é mais considerado um grupo válido pela perspectiva filogenética. Nos livros 1, 5, 6 e 8 há descrição da divisão Pteridophyta ou Pterophyta, que corresponderia ao grupo das samambaias ou "pteridófitas" sensu strictu. Porém, esse termo é desatualizado e deveria ser substituído por Monilophyta.

\section{Considerações finais}

Esta pesquisa evidenciou que os erros conceituais de Sistemática Vegetal são frequentes nos livros didáticos. A "reprodução das plantas" foi a temática que apresentou maior quantidade de erros conceituais. Dada a complexidade das estruturas reprodutivas e ciclos de vida, as "sobregeneralizações" acabaram se sobressaindo. É importante que os autores dos livros deixem de usar termos como "exclusiva" ou "apenas" para não restringir as diversas possibilidades no que tange à reprodução dos organismos.

A grande maioria dos erros referentes à "evolução das plantas" é a que pode impactar de maneira mais negativa a aprendizagem dos estudantes, uma vez que compromete o "pensar em árvore", umas das competências essenciais para alfabetização científica. Embora os livros apresentem algumas árvores filogenéticas, os textos dos capítulos não são condizentes com elas e refletem um pensamento linear de evolução ou, muitas vezes, baseado em outras escolas de classificação que não a cladística. Dessa forma, os livros didáticos de Biologia do PNLD apresentam dissonâncias em relação à epistemologia da escola filogenética. Faz-se necessário, portanto, que eles introduzam o assunto de forma ampla, não apenas em figuras que mostram cladogramas, mas, principalmente, por meio de explicações nos textos, possibilitando o entendimento da biodiversidade sob o olhar da evolução.

Em relação à taxonomia, é evidente que os livros se utilizam de classificações desatualizadas dos táxons de plantas. A utilização de nomes corretos e atualizados é essencial para que os alunos se apropriem da linguagem científica adequada na Biologia, o que facilita $o$ entendimento e a comunicação na área, além de permitir que o saber aprendido na escola esteja mais próximo do saber sábio (científico). 
DOI: http://doi.org/10.46667/renbio.v14i1.414

Por fim, é importante destacar que os erros conceituais presentes nos livros didáticos analisados podem passar despercebidos por parte dos professores que se utilizam dessas obras, uma vez que muitos podem não dominar determinados conteúdos, principalmente de Botânica, área na qual a formação inicial ainda é deficitária.

Espera-se que este trabalho possa ajudar professores de ensino básico na identificação de erros conceituais de Botânica nos materiais didáticos escolhidos e/ou produzidos por eles, assim contribuindo para melhorar o processo de transposição didática. Espera-se, também, que os autores de livros didáticos, editoras e equipes avaliadoras do MEC possam utilizar-se dos dados aqui produzidos para aprimorar suas obras e que trabalhos como este sejam apresentados aos professores em cursos e programas de formação continuada para que eles tomem ciência destes erros conceituais e possam ressignificar o material didático em suas práticas pedagógicas.

\section{Agradecimentos}

Os autores agradecem ao Prof. Dr. Peterson Lasaro Lopes, do Instituto Federal de Educação, Ciência e Tecnologia de São Paulo pela leitura crítica de trechos deste artigo. Dois revisores anônimos fizeram críticas e sugestões muito importantes para a melhoria do texto e a eles também somos gratos. Agradecemos, ainda, à Profa. Cristiane Bastos Ferreira pela revisão gramatical do texto, à Profa. Úrsula Fernal pela revisão do Abstract e à Profa. Thais de Souza Muci Boueri pela revisão do Resumen.

\section{Referências}

AMATO-LOURENÇO, L. F.; MOREIRA, T. C. L; ARANTES, B. L.; FILHO, D. F. S.; MAUAD, T. Metrópoles, cobertura vegetal, áreas verdes e saúde. Estudos Avançados, v. 30, n. 86, p. 113-130, 2016.

APG IV. An update of the Angiosperm Phylogeny Group classification for the orders and families of flowering plants: APG IV. Botanical Journal of The Linnean Society, v. 181, n. 1, p. 1-20, 24 mar. $/ 2016$.

BIZOTTO, F. M.; GHILARDI-LOPES, N. P.; MORPHY, C. D. S. A vida desconhecida das plantas: concepções de alunos do Ensino Superior sobre evolução e diversidade das plantas. Revista Electrónica de Enseñanza de las Ciencias, v.15, n.3, p.394-411, 2016.

BRASIL. Ministério da Educação. PNLD - Apresentação. 2011. Disponível em: http://portal.mec.gov.br/index.php?option=com_content\&view=article\&id=12391:pnld\&catid $=318$ :pnld\&Itemid=668 . Acesso em: 20 abr. 2019.

BRASIL. Ministério da Educação. Secretaria de Educação Básica. Fundo Nacional de Desenvolvimento da Educação. Guia de livros didáticos: PNLD 2018 - Biologia: Ensino Médio. Brasília: MEC/SEB, 2017. 
DOI: http://doi.org/10.46667/renbio.v14i1.414

CARDOSO-SILVA, C. B.; OLIVEIRA, A. C. Como os livros didáticos de biologia abordam diferentes formas de estimar a biodiversidade? Ciência \& Educação, Bauru, v. 19, n. 1, p. 169-180, 2013.

CORDEIRO, R. S.; MORINI, M. S. C.; FRENEDOZO, R. C.; WUO, M. Abordagem de sistemática filogenética com ênfase em biodiversidade nos livros didáticos. Acta Scientiae, Canoas, v. 20, n. 4, p. 610-625, 2018.

CHECOM, R. L. A.; AOYAMA, E. M. Análise comparativa do conteúdo de Botânica nos livros didáticos do Ensino Médio. In: SIMPÓSIO SOBRE BIODIVERSIDADE DA MATA ATLÂNTICA, 3., 2014, Santa Teresa. Anais do... Santa Teresa: Sambio, 2014. p. 261-268.

CHEVALLARD, Y. La transposition didactique: du savoir savant au savoir enseigné. Paris: La Pensee Sauvage, 1991.

DRAVIGNE, A.; WALICKZEK, M.; LINEBERGER, R. D.; ZAJICEK, J. M. The effect of live plants and window views of green spaces on employee perceptions of job satisfaction.

Hort Science v. 43, n. 1, p. 183-187, 2008.

EL-HANI, C. N.; KAWASAKI, C. M. Uma análise das definições de vida encontradas em livros didáticos de Biologia do Ensino Médio. In: ENCONTRO PERSPECTIVAS DO ENSINO DE BIOLOGIA, 8., 2002, São Paulo. Coletânea do... São Paulo: Edusp, 2002.

EVERT, R. F.; EICHHORN, S. E. Biologia vegetal. 8. ed. Rio de Janeiro: Guanabara Koogan, 2014.

FIDANZA, K. A Biodiversidade e o papel do taxonomista. Boletim ABLimno, v. 42, n. 2, p. 13-16, 2016.

FRANÇA, V. H.; MARGONARI, C.; SCHALL, V. T. Análise do conteúdo das leishmanioses em livros didáticos de ciências e biologia indicados pelo Programa Nacional de Livros Didáticos (2008/2009). Ciência \& Educação, Bauru, v. 17, n. 3, 2011.

FRANZOLIN, F.; TOLENTINO-NETO, L. C. B.; BIZZO, N. M. V. Generalizações que distanciam os conhecimentos dos livros didáticos das referências em genética. Genética na escola, v. 9, n. 2, p. 92-103, 2014.

FRENEDOZO, R. C.; MACIEL, M. D.; DIAS, M. A.; RIBEIRO, J. C.; CALEJON, L. M.; CANCIAN, M. A. E. Análise de livro didático de Biologia para o Ensino Médio: as abordagens e métodos aplicados ao ensino de Botânica. In: ENCONTRO NACIONAL DE PESQUISA EM EDUCAÇÃO EM CIÊNCIAS - ENPEC, 5., 2005, Bauru. Atas do... Bauru: ABRAPEC, 2005.

FUTUYMA, D. J. Biologia evolutiva. Ribeirão Preto: Sociedade Brasileira de Genética/CNPq, 1996. 
DOI: http://doi.org/10.46667/renbio.v14i1.414

GREGORY, T. R. Understanding evolutionary trees. Evolution: education and outreach, v. 1, n. 2, p. 121-137, 12 fev. 2008.

GUIMARÃES, M. A. Cladogramas e evolução no ensino de biologia. 2005. 233 f.

Dissertação (Mestrado em Educação para Ciência) - Faculdade de Ciências, Universidade

Estadual Paulista, Bauru.

HERSHEY, D. R. A historical perspective on problems in Botany teaching. The American Biology Teacher, v. 58, n. 6, p. 340-347, 1996.

HERSHEY, D. R. Avoid misconceptions when teaching about plants. 2004. Disponível em: http://www.actionbioscience.org/education/hershey.html . Acesso em: 20 abr. 2019.

HERSHEY, D. R. More misconceptions to avoid when teaching about plants. 2005.

Disponível em: http://www.actionbioscience.org/education/hershey3.html . Acesso em: 20 abr. 2019.

JUDD, W. S.; CAMPBELL, C. S.; KELLOGG, E. A.; STEVENS, P. F.; DONOGHUE, M. J. Sistemática Vegetal: um enfoque filogenético. 3. ed. Porto Alegre: Artmed, 2009.

KINOSHITA, L. S.; TORRES, R. B.; TAMASHIRO, J. Y.; FORNI-MARTINS, E. R. A botânica no ensino básico: relatos de uma experiência transformadora. São Carlos: RiMa, 2006.

KRASILCHIK, M. Prática de ensino de biologia. 4. ed. São Paulo: Edusp, 2004.

LOPES, E. R.; VASCONCELOS, S. D. Representação e distorções conceituais do conteúdo 'filogenia' em livros didáticos de biologia do ensino médio. Revista Ensaio, v. 14, n. 3, p.149-165, 2012.

LOPES, P. L. (ed). Águas Livres: a biodiversidade no ensino básico. Rio de Janeiro: Autografia, 2015.

MACEDO, M.; KATON, G. F.; TOWATA, N.; URSI, S. Concepções de professores de Biologia do ensino médio sobre o ensino aprendizagem de Botânica. In: ENCONTRO IBERO-AMERICANO SOBRE INVESTIGAÇÃO EM ENSINO DE CIÊNCIAS, 4., 2012, Porto Alegre. Anais do... Porto Alegre: URFGS, 2012.

MARINHO, L. C.; SETÚVAL, F. A. R.; AZEVEDO, C. O. Botânica geral de angiospermas no ensino médio: uma análise comparativa entre livros didáticos. Investigações em ensino de ciências, v. 20, n. 3, p. 237-258, 2015.

NEVES, A.; BÜNDCHEN, M.; LISBOA, C. P. Cegueira botânica: é possível superá-la através da educação? Ciência \& Educação, v. 25, n. 3, p. 745-762, 2019.

NOGUEIRA, A. C. de O. Cartilha em quadrinhos: um recurso dinâmico para se ensinar botânica. In: ENCONTRO "PERSPECTIVAS DO ENSINO DE BIOLOGIA”, 6., 1997, São Paulo. Coletânea do... São Paulo: USP, 1997. 
DOI: http://doi.org/10.46667/renbio.v14i1.414

NOVICK, L. R.; CATLEY, K. M. Fostering 21st-century evolutionary reasoning: teaching tree thinking to introductory biology students. CBE-Life Sciences Education, Bethesda, v. 15, n. 4, p.66, dez. / 2016.

PATATT, K.; ARAÚJO, M. C. P. de. Abordagens de atividades experimentais de botânica nos livros didáticos do ensino médio e sua importância no ensino e aprendizagem de biologia. In: ENCONTRO REGIONAL SUL DE ENSINO DE BIOLOGIA, 6., 2013, Ijuí. Anais do... Ijuí: Unijuí, 2013.

PPG I. A community-derived classification for extant lycophytes and ferns. Journal of Systematics and Evolution, v. 54, n. 6, p. 563-603, nov. 2016.

RAN, J. H.; SHEN, T. T.; WANG, M. M.; WANG, X. Q. Phylogenomics resolves the deep phylogeny of seed plants and indicates partial convergent or homoplastic evolution between Gnetales and angiosperms. Proceedings of The Royal Society B: Biological Sciences, v. 285, n. 1881, p. 1-9, 20 jun. 2018.

RIBEIRO, W. A.; GÜLLICH, R. I. C. Ensino de botânica na perspectiva do livro didático de biologia do ensino médio. In: CONGRESSO INTERNACIONAL DE EDUCAÇÃO CIENTIFICA E TECNOLÓGICA, 4., 2017, Santo Ângelo. Anais do... Santo Â̂ngelo: URI, 2017.

SANTOS, C. M. D.; CALOR, A. R. Using the logical basis of phylogenetics as the framework for teaching biology. Papéis Avulsos de Zoologia, v. 48, n. 18, p. 199-211, 2008.

SARTIN, R. D.; MESQUITA, C. B.; SILVA, E. C.; FONSECA, F. S. R. Análise do conteúdo de Botânica no livro didático e a formação de professores. In: ENCONTRO NACIONAL DE ENSINO DE BIOLOGIA - ENEBIO, 4., 2012; ENCONTRO REGIONAL DE ENSINO DE BIOLOGIA DA REGIONAL, 4., 2012, Goiânia. Anais do... Goiânia: SBEnBio, 2012. p. 1-9.

SEPULVEDA, C.; EL-HANI, C. N. Controvérsias sobre o conceito de adaptação e suas implicações para o ensino de evolução. In: MORTIMER, E. F. (Ed.). Atas do... VI ENPEC. Florianópolis: Abrapec, 2007.

SILVA, C. H.; SILVA, R.; NASCIMENTO, A. R.; MELO, C. A.; RIBEIRO, F.P.B; ALBUQUERQUE, D. F.; PONTES, N. E.; GUIMARÃES, W. N. R. A abordagem de atividades práticas no ensino da botânica nos livros didáticos de Biologia do ensino médio. In: JORNADA DE ENSINO, PESQUISA E EXTENSÃO, 9., 2009, Recife. Anais da... Recife: UFRPE, 2009.

SIMPSON, M. G. Plant systematics. 2. ed. Cambridge: Academic Press. 2010.

SIQUEIRA, M.; PIETROCOLA, M. A transposição didática aplicada a teoria contemporânea: a física de partículas elementares no ensino médio. In: ENCONTRO DE PESQUISA EM ENSINO DE FÍSICA, 10., 2006. Anais do... Londrina, 2006.

SOUZA, C. L. P.; GARCIA, R. N. Uma análise do conteúdo de botânica sob o enfoque Ciência-Tecnologia-Sociedade (CTS) em livros didáticos de biologia do ensino médio. Ciência \& Educação, Bauru, v. 25, n. 1, p. 111-130, jan. 2019. 
DOI: http://doi.org/10.46667/renbio.v14i1.414

SPIRO, M. D.; KNISELY, K. I. Alternation of generations and experimental design: a guided-inquiry lab exploring the nature of the her1 developmental mutant Ceratopteris richardii (C-fern). CBE-Life Sciences Education, Bethesda, v. 7, p. 82-88, 2008.

URSI, S.; BARBOSA, P. P.; SANO, P. T.; BERCHEZ, F. A. S. Ensino de botânica: conhecimentos e encantamento na educação científica. Estudos avançados, São Paulo, v. 32, n. 94 , p. 7-24. 2018.

VASCONCELOS, S. D.; SOUTO, E. O livro didático de ciências no ensino fundamental proposta de critérios para análise do conteúdo zoológico. Ciência e Educação, Recife, v. 9, n. 1, p. 93-104, 2003.

XAVIER, M. C. F.; FREIRE, A. S.; MORAES, M. O. A nova (moderna) biologia e a genética nos livros didáticos de biologia no ensino médio. Ciência \& Educação, Bauru, v. 12, n. 3, p. 275-289, 2006.

ZABALA, A. A prática educativa: como ensinar. Porto Alegre: Artes Médicas Sul., 1998.

Recebido em novembro de 2020. Aprovado em abril de 2021.

Revisão gramatical realizada por: Cristiane Bastos Ferreira

E-mail: bastosfcris@gmail.com 